$\Phi=\Phi$

\title{
An estimation of willingness to pay for secondary health care services in Tamil Nadu, India
}

\author{
K. Ramu \\ Assistant Professor, Department of Economics, Annamalai University, Annamalai Nagar 608 002, Tamil Nadu. India \\ *Corresponding author E-mail: kramueco@yahoo.co.in
}

\begin{abstract}
The present study has estimated the willingness to pay (WTP) for secondary health care services (SHCS) in rural and urban environment of three districts in the state of Tamil Nadu during 2009-2011. Since the governments are struggling to mobilise additional financial resources to provide essential health care services to the deprived population in the country, assessing the WTP for utilising the public health care services are realised as very important at this juncture. In realizing the importance of augmentation of resources, it has been decided to introduce contingent valuation method (CVM) for WTP of SHCS. A disproportionate systematic random sampling method has been adopted for the selection of 720 households; representing 240 respondents from each of the three districts represent 120 from rural and 120 from urban. A major portion (92\%) of the surveyed respondents' gender was male, literacy was high (90\%) and they belonged to productive age group. They generally involve themselves in the farm and non - farm activities and avail employment. Their per capita income is Rs.17871, and it is lower than the India's PCI. The SHCS are classified into 26 categories as per the guidelines provided by public health medical officers in the state of Tamil Nadu. The different health care services started with entry fee to dental problem. The 98.6 per cent of the total surveyed respondents are ready to pay for SHCS in a public hospital and the remaining 2.4 per cent of them are not willing to pay for the same. The range of WTP for 26 SHCS is Rs. 2 - 7000; the range of mean value is Rs. 6 - 5008 and the range of SD is $2-2854$. Considering the view of majority of the respondents, this study prescribes to introduce the range of user fee for the identified major public health care services. Since the range is differed significantly, it is suggested to follow the minimum amount initially and in a phased manner, the policy makers may prescribe to enhance the user fee after assessing the ground realities and loopholes. The estimated R2 value for SHCS is 20 per cent, which indicates that the selected 12 independent variables have low influence on WTP for SHCS. The study reports that the other exogenous factors like intensity of disease, accessibility of services, quality, urgency, need and perception are the predominant determinants of WTP for SHCS. The present research contends that constitution of district level co-ordination committee for fixing and implementing user fee for SHCS. Introduction of nominal fee (user fee) for SHCS may be fixed for affordable population, free services for BPL population and it would improve the efficiency and equity of the public health care services for the marginalised population. Finally, it is of utmost importance for health professionals to follow ethics in their profession.
\end{abstract}

Keywords: Willingness to Pay; Secondary Healthcare Services; User Fee; Public Health; Private Health; Acute and Chronic Diseases and Cost.

\section{Introduction}

The present study analyzes the willingness to pay (WTP) for secondary health care services (SHCS) in Tamil Nadu. Good health is an important prerequisite for labour productivity and socio-economic development. Health assumes even greater significance in a developing country like India. There have, indeed, been large gains in health status since independence as reflected in the substantial rise of life expectancy, and fall in infant mortality, besides reduction in crude birth rate. Life expectancy went up from 49 years in 1971 to 67 years in 2012. Infant mortality rate (IMR) was brought down from 129/1000 population in 1971 to $48 / 1000$ population in 2012. Crude birth rate had been reduced from 36.9 in 1971 to 23.5 / 1000 population and crude death rate from 14.9 to $7.5 / 1000$ population in the same period (Statistical outline of India 2012 and HDR 2012). One of the major reasons for these gains has been the development of an impressively vast, three-tiered health system of primary, secondary and tertiary health care infrastructure. But these developments are inadequate, and these performances of India in terms of various health development indicators are relatively low in the global context. For example, the life expectancy of China, Sri Lanka, Thailand, Brazil, and Malaysia is 82.5, 74.4, 69.3, 72.9 and 74.7 years respectively. In the same way they gained better in IMR with $30,13,23,33$, and 7 per 1000 population respectively in the same year (HDR 2012). These facts emphasize that strengthening of public health system is an important task for the government.

Better health, in terms of reduced morbidity and mortality and improved living standards, becomes an end in itself. Moreover, people are energetic and productive when they are in good health; thus, improved health status leads to higher economic growth and greater wealth (World Bank 1993:17). Poor health status of the people would create adverse consequences on the economy. It includes micro and macro effects; micro effects are impact on schooling, disability increase, productivity diminishes income loss, higher medical expenses and low consumption, low saving and low investment. The macro effects are impact on labour quality and labour supply, loss of aggregate production, low capital formation, higher disease burden and higher public health expenditure. Finally these adverse effects would reduce the 
economic growth (Ramu and Elango 2006:4). This brings into focus the need for provision of better quality health care services through public health system. Specifically the question arises whether the people who demand health care service could be made to share the burden of cost, the extent being determined by their affordability. Generating financial resources for meeting health care expenditure is one of the major challenges in the developing countries. The existing situation warrants them to introduce innovative methods to raise funds for the provision of health care services. However, raising health care tariff is not the only option to meet the public health care expenditures. Due to changes in the rural environment, specifically in the adoption of modern technologies and the radical changes in the climate, the socially and economically deprived classes in the rural and urban areas face different new health problems. They are paying higher fee for the health care services and also they forego income daily and productivity. The process of increasing net rural to urban emigration and growing urbanization in India need to be kept in mind and possibly the urban - health care needs to be accorded equal importance towards improvement of quality of life in India. By 2026 about 36 percent of India's population is expected to be urban. About two third of the total population growth in India by 2026 will end up living in urban sector (Mari Bhat 2001 and Dyson 2004).The burden of disease/infection leads to a sense of deprivation regarding health and production. The incidence of disease/infection not only depletes household income and savings but also diverts resources away from other productive investment activities. Hence their economic losses increase gradually and they are forced to fall in the debt trap (Kavitha and Ramu 2010:1) Developing new financial mechanisms such as user fee can shield public health sector from financial crisis and would leads quality, equity and reduction of disease burden. At this juncture, a number of questions emerge: Are people willing to pay for SHCS and if so how much? What are factors determine their willingness to pay (WTP)? Do they have the ability to pay (ATP)? Do they have affordability to meet the cost of health care? To answer these questions it is important to study the demand for SHCS and WTP for the same. In view of this, the present study on WTP for SHCS in public health sector of Tamilnadu has been conducted.

\section{Research problem}

Health is a prime input for human development. Improved health could enhance the economic growth of a nation. In India, where the only asset most people have is their physical body, health assumes greater significance. In general, secondary health care infrastructure provides advanced health care services to the urban population as well as to rural population, whereas such facilities are not at all available in the primary health care. Primary health care is the first level contact of an individual for their minor ailments. But the secondary health care role is very important in the three tier public health care system. It caters services to the rural and urban population for their common, acute and chronic diseases. Therefore, higher allocation of resources and strengthening of secondary health care system is warranted. In India the private health care spending is much higher than government spending in comparison to what is observed in many developing countries. The share of out-of-packet in total expenditure on health is the highest in India in comparison to the selected developing countries. This reflects on significant financial burden on households. Indeed the healthcare costs are believed to be one of impoverishment in India. It is estimated that around 63.22 million individuals or 11.88 million households were pushed to below poverty line (BPL), owing to health care expenditure in 2004 (Berman 2010:65). Furthermore outpatient care is more impoverishing than inpatient care in urban and rural areas alike. The financial burden on households is much higher if the patient is treated in a private hospital (Anil Gumber 1997, Ramu 2007:415, Meeta et.al 2010:42, Andrew Mitchell 2011:16, PranabBardhan 2011,). The distributions of burden of disease between communicable and non-communicable disease in India are 50 percent and 33 percent respectively. It signifies the scarcity of resources in the public health system.

India has one of the lowest health budgets in the world. It is held that even 67 years of independence the public health sector (merit good) has not received necessary allocation of funds from the planners. The total public expenditure on health in India was meagre 1.3 percent of GDP in 2012. Budgetary allocations for non-salary recurring costs have declined consistently and as a result 8 to 10 percent of the budget is allocated for recurring expenses and 90 percent of budget is spent on health administration (Mangal 2004:1). This environment has adversely affected the quality and functioning of the healthcare delivery system. These facts emphasize that strengthening of public health sector is an essential task for the government. It is well recognized fact that the system of public delivery of health services in India today is in crisis (Ahmad et al 2005). The scarcity of necessary finances is a major obstacle to further progress in many developing countries like India (Abel Smith and Dua, 1988, Abel Smith 1992). Therefore introduction of user fee for public health services is assumes best alternative financing mechanism for resources mobilization. The proposed user fee resources could be utilized for improvement of hospital services, like sanitation, clean and green programme, electricity, water and drainage, repairs of transport vehicles and medical equipment and purchase of life saving drugs. Therefore study on willingness to pay for secondary healthcare services assumes much significance from both academic and policy perspectives. The lack of field information on WTP for SHCS poses the constraint for policy formulation and micro level financial reforms in health sector. Further, comparative study on rural and urban WTP for SHCS is scanty in academic and policy circle. In realizing the serious gap in the literature, it is necessary to study the potential willingness to pay secondary health care services. This can be implemented at regional/macro level, which will improve the quality of public health sector.

\section{Methodology}

After assessing the ground realities it has been decided to use both primary and secondary data. This study was carried out in three districts of Tamilnadu, where in the levels of development varied at different levels. Since the income and employment are positively related to health attainment of the population, the sampling design has been evolved on the basis of both PCI (per capita income) of the district and HDI (human development index). The per capita income of the State and districts are used for the selection of districts. As per the records of State Human Development Report (HDR 2003) the districts are broadly classified into three such as, high, medium and low on the basis of PCI and HDI. Equal weightage has been given to PCI and HDI to select one representative district from each category. Accordingly, the following districts are identified: (i) Erode (High), (ii) Dindigul (medium) and (iii) Thiruvannamalai (low). In view of assessing the WTP at different levels of population live in the study region, field survey is carried out and the survey design is given below.

\subsection{Selection of sample respondents}

In each district, one municipality and one block are identified on the basis of grades of municipality and the levels of the block development. Totally, three urban areas and three rural areas have been covered for this study. From each municipality and block, 120 households are selected. A disproportionate systematic random sampling method has been adopted for the selection of households. Accordingly, every fifth of the household has been interviewed. Totally, 720 households are identified from the six areas comprising both rural and urban areas of three each. The secondary data for State health profile, districts health profile, 
demographic data, occupational pattern, district health care facilities, rate of public health utilization, morbidity pattern and cost of private health care system for different health problems, are collected from the Directorate of Public Health (DPH), Joint Director of Health Services (JDHS), Deputy Director of Health Services (DDHS), Assistant Director of Statistics and Private Health care System from the respective districts (Ramu and Selvarajan 2011)

\subsection{Computation and fixation of user fees}

Computation and fixation of price (user fee) for public health care services and classification of health problems of the people are a challenging task. For resolving this, a stakeholder meet was conducted in each district with participation of public health care providers which include Joint Director of Health Services (JDHS), Deputy Director of Health Services (DDHS), Municipal Health Officer (MHO), District Malaria Officer (DMO), Senior Medical Officers, and other District Health Programme Officers to facilitate the researchers. Around fifty medical officers participated in the meeting in all the three districts. Principal investigator of the project has highlighted the objectives and importance of the project and sought their cooperation. At the first level meeting, different health problems of the patients (common, acute and chronic diseases) have been identified and list of SHCS from entry fee to dental problems have been finalised. The participants of the meeting came out with different ideas in solving the problems and evolving guidelines for introducing user fee. Finally, Delphi technique was introduced to reach common consensus on the issues identified in the study. Base line data for Thiruvannamalai, Dindigul and Erode districts have been collected from the offices of the JDHS, Assistant Director of Statistics, Municipality and Blocks. The data comprise health profile of district, total population, number of wards in the municipalities and the socio economic profile of the municipalities and blocks With this backdrop, totally three municipalities (urban area) are chosen such as Thiruvannamalai from Thiruvannamalai district, Dindigul from Dindigul district and Bhavani from Erode district. Similarly, three blocks (rural areas) such as, Arani block, Palani block and Erode block are for this study from the respective districts.

In the process of assessing the WTP, an attempt has been made to elicit the opinions for fixing user fee for SHCS from the medical professionals working under the public health department, under the supervision of Joint Director of Health Services (JDHS) in the respective districts. First, sensitization has been done to the stakeholders of the meeting specifically to the medical officers and their co-operation sought. Based on the classification of SHCS five nominal prices (mini max value) are asked. Totally 45 senior medical professionals participated and gave their opinion in the prescribed format provided by us. They have provided five nominal prices for SHCS, after assessing the mini- max values. After the consensus, a five nominal user fee for SHCS have been identified. The interview schedule has been prepared and finalized by way of conducting pilot study and gathered suggestions from social scientists and community medicine experts. The pilot study was undertaken in Chidambaram municipality of Cuddalore district. The municipal region has been classified into four zones viz. South, North, West and East for identifying the sample from different clusters. Based on the classification, one ward has been selected from each zone randomly. In each ward, 10 households have been selected using systematic random sampling technique. The total sample size is reached to 40 households. The selected households have been interviewed with structured interview schedule and gathered quantitative and qualitative data, related to their socio-economic status, health seeking behaviour, system of medicine, cost of health care and willingness to pay for SHCS (Kumarasen and Ramu 2012). This process helped us in finalizing the interview schedule.

\subsection{Brain storming session}

One day brain storming meeting for validation of field data and fixing user fee for secondary health care services was conducted on April 6th 2010 at Annamalai University, Annamalai Nagar, Tamil Nadu. The experts in the subjects of medicine, economics, and commerce and population studies are participated. The experts have recommended that the prevailing market price (range of cost from mini to max value of private health care) of private health care is a bench mark value for fixing user fee for secondary health care services. Based on the suggestions by the experts, the user fee and interview schedule have been finalized for main field survey. There is a consensus to include rural area for assessing the willingness to pay for secondary health care services.

\subsection{Contingent valuation method}

Contingent Valuation Method (CVM) for WTP has been applied for this project. CVM is the most prevalent of the hypothetical valuation approaches. CVM employs survey techniques to ask people about the values that they would place on non-market goods, if markets did exist. The technique is known as CVM because the values (price of services) revealed by respondents are contingent upon the pseudo market area in the survey. Generally, the CVM is used to estimate economic values for all kinds of ecosystem and environmental services. During the last few years, there has been an increased interest in CVM of measuring WTP for health care services (Appel, et al. 1990, Donaldson 1990, Johannesson and Johnson 1991, Johanneson and Fagerberg 1992). Direct interview method was used, because it is most effective for complex questions. Questions are asked in close-ended formats (range of cost mini max value), also referred to as discrete choice. Respondents have been asked their willingness to pay for the SHCS at a given cost. Further, to elicit values (price) for public health services from respondents, the generally accepted and preferred method of discrete choice has been employed.

\subsection{Tools of analysis}

The study has employed percentage analysis to bring out degree of responsiveness of willingness to pay for the SHCS. To classify the respondents in terms of their WTP on SHCS, mean \pm SD have been used. Further, multiple linear regression analysis has been adopted to identify the major determinants of WTP. The results of the study are presented below.

\section{Results}

\subsection{Socio economic analysis}

The study was carried out in three districts of Tamilnadu during 2009 to 2011. The socio-economic analysis of the surveyed respondents of the three districts in the sate of Tamilnadu is as follows. This analysis would help in examining the determinants of willingness to pay for secondary health care services. Totally 720 respondents have been selected as sample, representing 240 respondents from each of the three districts represent 120 from rural and 120 from urban. The socio-economic profile comprises eleven indicators such as age, sex, education, occupation, community, type of family, family size, wealth status, income and annual expenditure. Each of these indicators has conceptual and decision making significance in examining the issues of willingness to pay for health care services. The age of the respondents has been classified into four such as 20-35 years (young), 36-50 years (middle), 51-65 years (upper middle), and $>65$ years (dependent) for this study. Of the surveyed 720 population, significant proportion $(41.25 \%)$ is middle age class, followed by upper middle age class $(30 \%)$ and young age class $(18.47 \%)$. Totally 90 per cent of the respondents are in the productive age class, and only 10 per cent of them are dependent 
population. It is observed that this study has active age class respondents and their opinion about willingness to pay for SHCS might be valuable for policy formulation. This has been witnessed in all the three study districts.

Out of 720 respondents, 92 per cent of the households are male and the rest $(8 \%)$ are female. It shows that the male heads lead the family and bear the entire responsibilities of the family including health care consumption. The same trend has been found in all the three study areas. The total literacy rate of the study districts (three) is 90 per cent. It is higher than India's literacy rate (74\%). The rural and urban literacy rates of the study region are 88 per cent and 93 per cent respectively. Agriculture stands as a predominant occupation (40\%). The next major employment providing sector is non-form sector $(28 \%)$ followed by business and others.

Backward community (BC) represents the highest share (67\%), at the next level Schedule Cast (SC) and Schedule Tribe (ST) shares 29 per cent followed by most backward cast (MBC) 28 percent Analysis about the type of family explains that 84 percent of the households have nuclear and the rest 16 percent of them are in joint family system. It is important to note that the nuclear family system is higher (88\%) in rural area than in urban area $(80 \%)$, status dwelling unit analysis shows that the majority $(92 \%)$ of the study population are in their own house, only 8 percent of them are in rented houses. The total family members of the surveyed respondents are 33831 of which 16417 are males and 17414 are females. The average size of the family is 4.3 ; which is less than the all India family size 4.5 (Census atlas of India 2001). The wealth has been divided into three major groups: low wealth possession $(<.5$ lakh), medium wealth possession (Rs.50001 - Rs. 1.5 lakh), and high wealth possession (above Rs. 1.5 lakh). It reveals that the medium wealth holders' share is 43 per cent of the total sample population, followed by high and low wealth holders, 29 per cent for the former and 28 per cent for the latter. When the rural and urban are compared, urban has higher share of medium wealth holders $(45 \%)$. This has been shown in all three study districts; it ranged from 39 per cent to 48 per cent. The annual income of the respondents includes income from employment, business, agriculture, non-farm activities, rent of land and house, and other sources. Finally gross income of an individual has been calculated with the current price in 2010-2011. This income has been grouped into three major classes (table 4.7), low income (<Rs. 0.5 lakh), middle income (Rs.50001 - 1, 00,000) and high income class (>Rs. 1, 00,001). It reveals that the middle income class shares 41 per cent among the three classes of income. At the next level the low income shares 39 per cent and high income class shares 20 per cent in the study areas. The estimated per capita income (PCI) of the study region is Rs.17871 at prevailing market price of 2010 - 11, and it is lower than the India's PCI, Rs 37,851 in 2012 (Statistical Outline of India 2012).

Assessment of household expenditure is another method for income calculation. The expenditure of the household has been grouped into five major categories such as food, education, health; entertainment and household management. These expenditure details are collected on monthly recall basis and it has been computed with the current market price, 2010-11. Annual household expenditure has been classified into four major categories viz., Rs.1000 - Rs.50000 (low income), Rs.50001 100000 (middle income), and Rs.100001-200000 (upper middle income) and above Rs.200001 (high income). It reveals that the upper middle income class shares 45 per cent among the four categories. At the next level the middle income shares 36 per cent followed by higher income class (10.4\%). A meagre study population is in the category of low income class $(8.5 \%)$. The estimated per capita expenditure of the study area is Rs.28245 per annum. The same for rural and urban are Rs. 27861 and Rs. 28614 respectively. The difference between PCI and annual expenditure of the respondents is 37 percent. Income and expenditure are the major determinants of health care consumption. These two factors may influence the willingness to pay for public health care services.

\subsection{WTP Analysis}

The total WTP for SHCS in the three districts is 98.61 per cent; only a meager study population $(1.39 \%)$ is not WTP for SHCS in the study area. Since the health services are being treated as merit good in earmarking the budget, the consumers are willing to pay for public health care services (PHCS) for availing better health services on par with private health care (Sharma 2001). A study by National institute of Health and Family Welfare (NIHFW) in the states of Assam, Gujarat, Madhya Pradesh, Uttar Pradesh, Delhi and Tamil Nadu reveals that most of the respondents (68\%) were willing to pay the user fee irrespective of educational status (Sharma and Bir 2000). Recent micro level studies on WTP for primary and SCHS in Tamil Nadu have shown that more than 95 per cent of the respondents are willing to pay to set right their health problems (Kumaresan and Ramu 2006, Suganyasundari and Ramu 2007)). Therefore the present analysis also shows higher amount of willingness to pay for SHCS in the study region. When the rural and urban respondents are compared, the WTP for SHCS is higher in urban area (99\%), followed by rural (98\%). It is observed that the rural populations are ready to pay for good quality health care services for their different health problems. It is a good sign for public health care market for policy formulation. District wise analysis has shown that more than 98 per cent of the surveyed population is WTP for SHCS in three districts and the range of WTP is from 98.33 per cent to 98.75 per cent (table 1).

The secondary health care services (SHCS) are classified into 26 categories as per the guidelines provided by public health medical officers in the state of Tamil Nadu. The different health care services started with entry fee to dental problem (Table 2).The descriptive analysis for WTP for SHCS in three districts is presented in table 2. The range of WTP for 26 health care services in three districts is from 82.64 per cent to 97.50 per cent and the not WTP for the same is from 2.50 per cent to 17.36 per cent. It is interesting to observe that 96.25 per cent of the surveyed respondents are willing to pay entry fee availing in the government hospital services. The Tamil Nadu government introduced Veranda fee i.e. registration fee during the year of 2001-2006 in order to solve the problems of space and beds on time being. But the response was poor from the public. The present study has explored the possibilities in introducing of entry fee in the government hospitals. The proposed range of entry fee is from Rs. 2 to 5, the mean value is Rs. 6 and standard deviation (SD) is 5 . The SD is smaller than mean value; it represents the high degree of uniformity of the respondents' opinion and homogeneity of the present data.

Following the principles of medical science, the diseases are classified into three categories i.e., common diseases (fever, cold, headache, vomiting, dysentery, body ache, etc), acute infection/ disease (Malaria, Typhoid, Jaundice, Acute diarrhea diseases (ADD), upper respiratory infection (URI), lower respiratory infection (LRI), viral fever, H1N1, SARS, Trauma Care etc) and chronic infection / disease (Leprosy, Cancer, TB, Cardio vascular diseases, Diabetes, HIV/AIDS, Asthma, etc.,). In this context, the WTP for these diseases has been undertaken. The majority of the surveyed population (98\%) is WTP for their common diseases in government hospitals; only 2.5 per cent of them are not WTP for their common health problems; the range of cost of WTP for common diseases is Rs. 20-200; the mean value is Rs. 64 per visit and the SD is 32. The WTP for acute disease is 97 per cent and the not WTP for the same is only 3 per cent. The range of cost (WTP) for acute diseases is Rs. $20-1700$. The mean value is Rs. 188 per visit and SD is 157. For chronic infection or disease the WTP is 95 per cent and the not WTP is nearly 5 per cent. The range of cost (WTP) per visit is Rs. $50-1200$, the mean value is Rs. 231 and the SD is 209. A comparison of the three diseases (Common, Acute and Chronic) shows that the chronic disease has less WTP than others. This analysis reports that the SD for three diseases is lower than the mean values. It shows the high degree acceptance from the respondents for WTP (table 2). 
Laboratory examinations such as blood, stool, sputum, malaria, diabetes, HDL, LDL, Jaundice, HIV, AIDS, etc, are essential often in the modern world. Owing to climatic changes and global warming, human population is at the risk of new health hazards. In this environment, good laboratory facility is important for catering to the needs of the community. The laboratory tests are classified into three, such as common blood examinations (grouping, viral infection, malaria, diabetes, etc.) special or higher level blood examinations (HD / LDL cholesterol, jaundice, tropical pulmonary eosinophilia (TPE), glucose tolerance test (GTT), HIV/AIDS, TB, and etc) and other lab examinations (stool, sputum, biopsy, tissue culture, etc). In addressing to these questions, these present WTP analysis for these examinations has been carried out. 96 per cent of the surveyed respondents have agreed to pay for common blood test in the public hospitals. The WTP ranges from Rs. 20-150 per common blood test, the mean value is Rs. 64 and SD is 26 . The special blood tests WTP ranges between Rs. 30 and 850 per test, the mean value is Rs. 158 and SD is 157. And for the other lab examinations, the WTP ranges from Rs. 40 - 200, the mean value is Rs. 109 and SD is 34. Finally it is observed that more than 96 per cent of the study population has agreed to pay for laboratory test in public hospital. Studies reveal that the quality of public health care services is being deteriorated and thereby the demand for private health care has increased (Mathiyazhagan 1998, Anil Gumber 2001, Duraisamy 2002, Narrayana 2003, Deepasankar 2003, Mangal 2004, Ravi Duggal, et al. 2006 and Ramu 2007). In realizing the existing problems, the present study provides an insight for strengthening the laboratory services in public hospitals Blood transfusion is one of major health care activities prevail at present due to frequent road traffic accidents (RTA), trauma care and nutritional deficiencies. Nearly 94 per cent of the study population has reported that they are ready to pay for blood transfusion. The minimum and maximum WTP for this service is Rs. 100 - 2500, the mean value for the same is Rs. 695 and SD is 418. Child delivery is one of the predominant functions in the human life cycle. In the modern world, there are two types of deliveries i.e. normal delivery and caesarean delivery. The cost of delivery is too high in private health sector. The prevailing private market price for normal and caesarean deliveries is ranged from Rs. 3000 to Rs. 5000 for the former and Rs. 15000 to Rs. 25000 for the latter. The affordability of the poor and marginalized in rural and urban population for this service in private health system is a matter of discussion. The total WTP for normal delivery is 90 per cent and it is important to say that the 10 per cent of the study population could not pay for normal delivery services in the public hospitals. The WTP ranges from Rs. 2000 - 4000 per normal delivery, the mean value is Rs. 1969 and SD is 791. There is an overwhelming response from the public for WTP for caesarean delivery in the public health hospitals. The total WTP for this service is 92 per cent, the range of WTP for the same is Rs. 500 15000 , the mean value is Rs. 5008 and SD is 2854 . Therefore they are ready to pay on an average Rs. 2000 for normal and Rs. 5000 for caesarean delivery in a government hospital if the quality of service is good.

Snake, animal and insect bites are common in rural and semiurban areas. The economic and health consequences of these bites are enormous and the treatment cost of this problem is also high. So the total WTP for this service is 87 per cent and a considerable section of 13 per cent respondents is not WTP for these problems. The range of WTP for this service is Rs. 50 - 300 per visit, the mean cost is Rs. 1089 and SD is 636. It is concluded that each individual is ready to pay Rs. 1100 for these bites per episode. Rapid industrialization and introduction of new economic policy (NEP) have led to manifold increase in transport of population. In this context, the incidence of RTA is also high in the industrialized world. So provision for trauma care and minor operational services is necessary for saving the human life at the time of emergency. More than 88 per cent of the study respondents have accepted to pay for minor operation and accidental problem in the public health care system. However, 13 per cent of them are not WTP for the same. This finding has to be viewed carefully for policy formulation. The range of WTP for this service is Rs. 50 4000 , the mean value is Rs. 610 and SD is 532 .

More than 90 per cent of the households are in the category of nuclear family system. The traditional joint family system has broken down due to fusion and fission of families. Lack of adjustment, tolerance and mutual understanding has contributed to higher stress and frustration in the family life. Recent study on occupational diseases has shown that the psychological hazard is a major health problem in industrial environment (Thangalakshmi and Ramu 2010). Thus, suicide attempt has increased; therefore the present WTP for poisoning cases has been carried out. The total WTP for this problem is 87 per cent and the remaining 13 per cent of them are not WTP for the same. The range of WTP for this is Rs. $100-6000$, the mean value is Rs. 1465and SD is 1047 (Table 2).

The X-Ray, ECG, Scan, CT scan, MRI scan and endoscope examinations are important for a clear understanding of health problems. The cost of these examinations is high in private health sector. Further, the maintenance and operation of this equipment also requires higher recurrent cost. Treatment or hospitalization in private health sector for chronic illness often means the liquidation of meagre assets, even permanent indebtedness, and one episode of hospitalization is enough to wipe out all the assets of the family. The present analysis may pave way for reducing the cost of health care services. Nearly 96 per cent of the surveyed respondents are WTP for X-Ray tests, the range of payment for this test is Rs. $15-100$, the mean value is Rs. 51 and SD is 15 . For ECG test the WTP is 96 per cent, the mean value is Rs. 54, the range is Rs. 20-80 and SD is 11 . The normal scan examination has 96 per cent of WTP, CT scan examination has 95 per cent and the MRI scan test has 92 per cent. The overwhelming response from the public for these scan examinations is appreciable and it shows the vulnerability of various diseases. The WTP ranges of these are Rs. $20-500$, Rs. 100-2500 and Rs. 100 - 4000 respectively the cases mentioned. The mean values of these three are Rs. 204, 685, and Rs. 1445 and SD are 88, 411 and 748 respectively. For endoscope test, the total WTP is 92 per cent and the range of WTP is Rs. $25-2500$. The mean value is Rs. 978 and SD is 448.

The life expectancy of birth rate increased from 32 years in 1942 to 67 years in 2012 due to better health services. With sustained reduction in mortality and fertility rates combined with increased life longevity, the size of young cohort has reduced while the size of old cohort has increased. The estimated demographic data shows that the old age dependency ratio will go up from 13 per cent in 2000 to 33 per cent 2050. Further, it has been estimated that age of 60 years today is expected to survive another 15-25 years. The aged population is suffering from TB, Asthma, Cancer, Diabetes, Opthamological diseases (eye related problems), etc. In this context, treatment for Opthamological diseases for the aged population is creating additional private and social cost. Therefore, the WTP analysis for this service is 92 per cent and the range of WTP is Rs. $100-3000$. The mean value is Rs. 827 and SD is 456. Surgery or operation for, Ortho, Gastric, ENT, Thyroid and other problems is common in secondary health care services. The private cost for these surgeries is ranged from Rs. 500 to Rs. 15000 at current prices. Therefore, the WTP analysis for this service is necessary. Respondents around 89 per cent are WTP for this service. The range of WTP is Rs. 200 - 7000, the mean value is Rs. 1453 and SD is 1073.

Owing to changes in the rural environment, specifically in the adoption of modern technologies and the changes in the climate, the marginalized population in the rural and semi-urban areas faces various health problems. The rate of inpatient care has been increased manifold in the recent years. The analysis of WTP for bed cost per day would provide policy implications for the planners. More than 93 per cent of the study populations are WTP for bed cost per day. The range of WTP for the same is Rs. 10 - 300 per day. The mean value is Rs. 74 and SD is 46 . Ambulance service is essential at the time of emergency. It is important to observe that the 83 per cent of them have accepted 
that WTP per kilometre is Rs. $2.00-10.00$, the mean value is Rs. 5 and SD is 2.

Half of the Indians are diabetic patients in 2009 and most of them are insulin users. Owing to unhealthy food behaviour, kidney disorder is also common among the public. The cost of health care of the affected population has increased due to frequency of dialysis. Realizing this situation, an analysis of WTP is necessary for better quality of public health care services. The total WTP for dialysis per visit is 91 per cent and the remaining 9 per cent are not WTP for the same. The range of WTP is Rs. $100-2500$, the mean value is Rs. 780 and SD is 414 .

Rapid industrialization and climate changes have contributed a lot to air and water contamination. Owing to higher amount of pollution in air and water, the incidence of ear, nose and throat (ENT) infection / disease is high in recent years. These outbreaks require huge amount of money for treating these disorders. The present analysis reports that 96 per cent of them are ready to pay for ENT problems. The range of WTP is Rs. $20-500$ per visit, the mean value is Rs. 134 and SD is 65 . Good teeth are important for the smooth functioning of human body. Changes in consumption behaviour and using of packed food items have increased the dental problem in the modern civil society. The majority of the surveyed respondents $(96 \%)$ have accepted to pay for dental problem in the public hospital. The range of WTP is Rs. $50-800$ per visit for extraction, filling and other dental problems. The mean value is Rs. 251 and SD is 125 . The SD of 26 services in secondary health care services from entry fee to dental problem is smaller than the mean value of respective services. It shows a high degree of uniformity of the observation as well as homogeneity of data series. These major findings would provide guidelines for planners for policy formulation.
Over all, this study prescribes to introduce the range of user fee for the identified major health care services. Since the range is differed significantly, it is suggested to follow the minimum amount initially and in a phased manner, the policy makers may prescribe to enhance the user fee after assessing the ground realities and loopholes. The government use to introduce a lot of freebies for gathering vote for forming the new government. In this context, the people also will expect to provide these services at free of cost. Even though the health care demand is inelastic, the government has to disseminate the importance in provision of better health care services on par with private and corporate hospitals. The willingness to pay for enjoying various health care services is determined by the endogenous and exogenous factors. In this context, an attempt has been made to explore the factors in determining WTP. Hence the multi - variable technique is introduced and discussed below.

\subsection{Regression analysis}

Determinants of WTP are an important variable of interest. There are many factors which would influence the amount of WTP for SHCS. Hence, it is proposed to identify the determinants (variables), which contribute to WTP for SHCS. For this purpose, the multiple regression analysis has been carried out. The linear multiple regression equation is.

WTP $=$ Constant $+\mathrm{a}_{1}$ DD_Dind $+\mathrm{a}_{2}$ DD_TVM $+\mathrm{a}_{3} \mathrm{D} \_$Rural + $\mathrm{a} 4 \mathrm{Age}+\mathrm{a} 5 \mathrm{Educ}+\mathrm{a}_{6} \mathrm{D} \_\mathrm{MBC}$ Com + a 7 D_BC COM $+\mathrm{a}_{8} \mathrm{D} \_\mathrm{FC}$ $\mathrm{Com}+\mathrm{a}_{9}$ Famsize $+\mathrm{a}_{10}$ wealth $+\mathrm{a}_{11}$ Income + a12 no of visits.

Table 1: WTP for Public Health Care Services of the Surveyed Respondents

\begin{tabular}{|c|c|c|c|c|c|c|c|c|c|c|c|c|}
\hline & \multicolumn{3}{|c|}{$\begin{array}{l}\text { Thiruvannamalai } \\
(\mathrm{n}=240)\end{array}$} & \multicolumn{3}{|c|}{$\begin{array}{l}\text { Dindigul } \\
(\mathrm{n}=240)\end{array}$} & \multicolumn{3}{|l|}{$\begin{array}{l}\text { Erode } \\
(\mathrm{n}=240)\end{array}$} & \multicolumn{3}{|c|}{$\begin{array}{l}\text { Grand Total } \\
(\mathrm{N}=720)\end{array}$} \\
\hline & Rural & Urban & Total & Rural & Urban & Total & Rural & Urban & Total & Rural & Urban & Total \\
\hline Yes & $\begin{array}{l}118 \\
(98.33)\end{array}$ & $\begin{array}{l}119 \\
(99.17)\end{array}$ & $\begin{array}{l}237 \\
(98.75)\end{array}$ & $\begin{array}{l}117 \\
(97.50)\end{array}$ & $\begin{array}{l}119 \\
(99.17)\end{array}$ & $\begin{array}{l}236 \\
(98.33)\end{array}$ & $\begin{array}{l}118 \\
(98.33)\end{array}$ & $\begin{array}{l}119 \\
(99.17)\end{array}$ & $\begin{array}{l}237 \\
(98.75)\end{array}$ & $\begin{array}{l}353 \\
(98.06)\end{array}$ & $\begin{array}{l}357 \\
(99.17)\end{array}$ & $\begin{array}{l}710 \\
(98.61)\end{array}$ \\
\hline No & $2(1.67)$ & $1(0.83)$ & $3(1.25)$ & $3(2.50)$ & $1(0.83)$ & $4(1.67)$ & $2(1.67)$ & $1(0.83)$ & $3(1.25)$ & $7(1.94)$ & $3(0.83)$ & $\begin{array}{l}10 \\
(1.39)\end{array}$ \\
\hline Total & $\begin{array}{l}120 \\
(100)\end{array}$ & $\begin{array}{l}120 \\
(100)\end{array}$ & $\begin{array}{l}240 \\
(100)\end{array}$ & $\begin{array}{l}120 \\
(100)\end{array}$ & $\begin{array}{l}120 \\
(100)\end{array}$ & $\begin{array}{l}240 \\
(100)\end{array}$ & $\begin{array}{l}120 \\
(100)\end{array}$ & $\begin{array}{l}120 \\
(100)\end{array}$ & $\begin{array}{l}240 \\
(100)\end{array}$ & $\begin{array}{l}360 \\
(100)\end{array}$ & $\begin{array}{l}360 \\
(100)\end{array}$ & $\begin{array}{l}720 \\
(100)\end{array}$ \\
\hline
\end{tabular}

Source: Computed from primary data.

Note: Figures in parentheses denote percentage to total.

Table 2: WTP for Different Health Care Services in Three Districts (Over All)

\begin{tabular}{|c|c|c|c|c|c|}
\hline S.No & Services & WTP $(\%)$ & Range (Rs.) & Mean (Rs.) & S. D \\
\hline 1 & Entry Fee & 96 & $2-50$ & 6 & 5 \\
\hline 2 & Common Diseases & 98 & $20-200$ & 64 & 33 \\
\hline 3 & Acute Disease /Infection & 97 & $20-1700$ & 188 & 158 \\
\hline 4 & Chronic Infection & 95 & $50-1200$ & 232 & 209 \\
\hline 5 & Common Blood Examination & 96 & $20-150$ & 65 & 27 \\
\hline 6 & Higher Level Lab Examination & 96 & $30-850$ & 158 & 158 \\
\hline 7 & Other Lab Examination & 96 & $40-200$ & 110 & 34 \\
\hline 8 & Blood Transfusion & 94 & $100-2500$ & 696 & 418 \\
\hline 9 & Normal Delivery & 90 & $200-4000$ & 1969 & 792 \\
\hline 10 & Caesarean Delivery & 92 & $500-5000$ & 5008 & 2854 \\
\hline 11 & Animal Bites per Visit & 87 & $50-3000$ & 1089 & 636 \\
\hline 12 & Operation/Accident per Visit & 88 & $50-4000$ & 610 & 532 \\
\hline 13 & Poisoning Cases & 87 & $100-6000$ & 1466 & 1047 \\
\hline 14 & X - Ray & 96 & $15-100$ & 51 & 15 \\
\hline 15 & ECG test & 96 & $20-80$ & 54 & 11 \\
\hline 16 & Normal Scan Examination & 96 & $20-500$ & 204 & 88 \\
\hline 17 & CT Scan Examination & 95 & $100-2500$ & 686 & 411 \\
\hline 19 & Endoscope Test & 92 & $25-2500$ & 978 & 448 \\
\hline 20 & Opthamological Problem & 92 & $100-3000$ & 828 & 456 \\
\hline 21 & Surgery / Operation & 89 & $200-7000$ & 1454 & 1073 \\
\hline 22 & Inpatient Care/ Bed Cost per Day & 93 & $10-300$ & 74 & 47 \\
\hline 23 & Ambulance Service per Kilometer & 83 & $2-10$ & 5 & 2 \\
\hline 24 & Dialysis per Visit & 91 & $100-2500$ & 780 & 414 \\
\hline 25 & ENT Problem & 96 & $20-500$ & 134 & 65 \\
\hline 26 & Dental Problem & 96 & $50-800$ & 251 & 125 \\
\hline
\end{tabular}




\begin{tabular}{lll}
\hline WTP & $=$ & Willingness to pay \\
\hline DD_Dind & $=$ & District Dummy for Dindigul District (1 for Dindigul and 0 for others) \\
DD_TVM & $=$ & District Dummy for Thiruvannamalai District (1 for Thiruvannamalai and 0 for others) \\
D_Rural & $=$ & Regional dummy for rural (1 for rural and 0 for urban $)$ \\
Age & $=$ & Age in years \\
Edu. & $=$ & Education in years \\
D_MBC Com & $=$ & Community Dummy Variable for MBC ( 1 for MBC and 0 for others $)$ \\
D_BC Com & $=$ & Community Dummy Variable for BC ( 1 for BC and 0 for others $)$ \\
D_FC Com & $=$ & Community Dummy Variable for FC ( 1 for FC and 0 for others \\
Famsize & $=$ & Total Family members in numbers \\
Wealth & $=$ & Total value of wealth in ' 000 s \\
Income & $=$ & Total household Income per annum in ' $000 \mathrm{~s}$ \\
No. of visits & $=$ & Total number of visits made to private hospital \\
\hline
\end{tabular}

In order to assess the determinants of WTP, multiple regression analysis was carried out for SHCS. The amount of WTP for 26 services (entry fee to dental services) in SHCS is treated as dependent variable and the above 12 variables are used as independent variables for this regression analysis. Among the three study districts, as per human development index (HDI), Erode is the high HDI district, followed by Dindigul (medium) and Thiruvannamalai (low). Erode district is treated as reference district with other two districts. In view of different levels of development between urban and rural the urban area has been treated as reference area for dummy. The SC community is socially and economically deprived class in India and still they are lacking behind in economic development. The affordability for health care services may be low when compared with other developed communities. In this context, the SC community treated as reference value with other three communities such as MBC, BC and FC. The SC is kept as dummy variable.

The estimated $R^{2}$ values for 26 services (entry fee to dental services) are less than 20 per cent. However, the $\mathrm{R}^{2}$ value for blood transfusion is $0.960(96 \%)$. This regression model for determinants of WTP on related independent variable, reports that the selected 12 variables as mentioned earlier have lower impact on WTP for 26 services in a public health hospital. The study reports that the other exogenous factors like intensity of disease, accessibility of services, quality, urgency, need, etc, are the predominant determinants of WTP for SCHS. Hence, a longitudinal qualitative study is needed to assess WTP and their determinants. However, these statistical inferences would provide insights for fixing user fee for public health care services.

\subsubsection{Summary results of the determinants of WTP}

The discussed results on the determinants of the WTP for the various types of health care services are summarized by mentioning the directions of the relationship between the WTP and the various identified determinants in the Table 3 . Among the 26 (entry fee to dental services) related SHCS, the regression results show that the WTP of the people from Dindigul district is less than that of the beneficiary in Erode district; and it is relatively less for nearly 15 services among which 11 are statistically significant. The difference between the WTP for Erode and Thiruvannamalai district is significant for 15 services. For normal and caesarean delivery, the WTP in Thiruvannamalai district is significantly higher and for other 22 services, it is expected to be less than Erode district. Thus, the level of HDI is expected to have a significant influence on the WTP for SHCS.

Since the health awareness of the public in urban area is relatively higher, it is evident that the WTP for almost all type of services is less for the rural people. The regression results confirm that the difference in WTP is significant for 13 services. Even though age is expected to have influence on WTP, it is evident to have significant influence for only two services; viz dental and dialysis. At the same time, age has negative influence on the WTP for chronic diseases. Like age, it is evident that the educational qualification has positive influence on the WTP for all types of SHCS and it is significant for eight services (common, higher level lab test, other lab test, normal delivery, caesarean delivery, MRI scan, Opthamological services and ambulance services) out of 26 services. Further it is evident that the WTP between SC/ST and other communities differs for most of the selected SHCS; however, the difference of WTP between SC/ST and MBC is significant for normal delivery alone. The difference of WTP between SC/ST and BC community is significant for normal delivery, MRI scan, and the dental problems; however, for the common blood examination, the WTP by BC community is less than that of SC/ST. There is strong evidence to prove that the WTP of the FC people is relatively higher than that of SC/ST people for about 22 services among which 9 services are significant. Among the other major socio-economic variables, the increase in family size has negatively influenced the WTP, but it is less significant for most of the services. The other three related variables viz, wealth, income and number of visits seem to have positive impact on the WTP for majority of the SHCS; however, the impact of the income is less significant for most of the SHCS. It is evident to notice that the level of wealth status on the whole community as well as the number of visits has significant effect on the WTP for availing the various SHCS.

\section{Conclusion}

This study provides some concrete policy suggestions in order to strengthen the public health sector in Tamil Nadu and it may be introduced to national level for provision of quality and equity in health care services. It is hoped that if these policy recommendations are implemented they will help in achieving the goal of health for all and equitable provision of quality of public health care services to the community. The suggestions are made here on the basis of the field investigations carried out among 720 respondents of three urban and three rural areas in three districts of Tamil Nadu. Further, the research team came across various cases as they interact with district officials, programme officers and the public at the time of preliminary visits made to all three districts and select three blocks and select three municipalities in the state. In the light of the experience gained and the benefit of exposure that the team had during the last two years. The report attempts to register a few policy directions for future action.

- Constitution of district level coordination committee for fixing and implementing user fee for public health services.

- Pay ward in Government Hospitals (GH) may be introduced with high quality of service, which might get good response from the public.

- $\quad$ Nominal fee (user fee) for SHCS (curative services) may be fixed for affordable population and free services for BPL population.

$\mathrm{Hi}$ - tech multi-specialty hospital to be constructed in each district headquarters without disturbing the existing GHs for fee collection

Financial autonomy for user fee utilization by the $\mathrm{GH}$ authorities.

Place of institutional mechanism for periodic monitoring and evaluation of all GHs are necessary and reward / award for health care personnel for improvement of quality of service. 
- Constitution of district level quality assurance cell for public healthcare services and medicine.

Control of under table payment (bribes and tips) and special incentive / increment for clean public health personnel.

New drugs for diseases / infection to be supplied to the GHs instead of supplying the old type of medicines.

Separate ward for senior citizens and physically disabled population to be provided in GHs

Resource leakages to be stopped from public health institutions (medicines and others) and penalty for leakages.

Provision of non-practice allowance (NPA) for state public health doctors on par with central health personnel.

Awareness has to be created among the public for avoiding self- medication practice (availing health service directly from medical shop without doctor's advice).

Awareness has to be created among the population about the serious health risk involved in self-treatment.

- Banning of medical products advertisement in the mass media and severe penalty for these advertisements.

Awareness has to be created among medical professionals for following medical ethics in their profession.

Reduction of man power shortages in $\mathrm{GH}$ and proper maintenance of medical equipment are needed instead of keeping the machines out of order.

\section{Acknowledgement}

The author is grateful to the authorities of the University Grants Commission (UGC), New Delhi, who have funded this project and offered timely guidelines to carry out the study in time. I thank the Annamalai university authorities who offered administrative support and managerial services in carrying out the study.

\section{References}

[1] Abel Smith B (1986) Funding Health for all - is insurance the answer? World Health Forum, 7.

[2] Abel Smith B \& Dua A (1988), Community Financing in Developing Countries: The Potential for the Health Sector. Health $\begin{array}{lll}\text { Policy and } & \text { 3(2):95-108. }\end{array}$ http://dx.doi.org/10.1093/heapol/3.2.95.

[3] Ahmad JK, Devarajan S, Khemani \& Shah (2005) Decentralization and service delivery, World Bank policy Research Working Paper No. 3603.

[4] Andrew Mitchal, Ajay Mahal, \& Thomas Bossert (2011), Health care Utilization in Rural Andhra Predesh, Economic and Political Weekly, 25(5):15-19

[5] Anil Gumbar (2001) Extending Health Insurance to the Poor: Some Experiences from SEWA Scheme. Senior Economist, National Council of Applied Economic Research, New Delhi.

[6] Anil Gumber, (1997) Burden of disease and cost of ill - health in India: setting priority for health interventions during the ninth plan. Margin. 29:2.

[7] Appel LJ, Steinberg EP, Power NR, Anderson GF, Dwyer SA \& Faden RR (1990), The reduction from low osmolality contrast media: what do patients think it is worth? Medical Care, 28, 324 337.

[8] Com Donaldson (1990), Willingness to pay for publicly provided Goods, A Possible Measure of Benefit? Journal of Health Economics, 9:2201-2209.

[9] Deepa Shankar \& Vinish Kathuria (2003) Health sector in 2003 - 2004 Budget. Economic and Political Weekly, 12:76-83

[10] Duraisamy (2002), Public-Private choice and the cost of health care in Tamil Nadu. The Second Symposium on the Private - Public mix in Health Development in India. A Lesson from Canadian Experience - Organized by Institute of Social and Economic Change and Indo Shastri Canadian Institute, Bangalore, 27-29.

[11] Dyson Tim, \& Visaria Pravin (2004) Migration and Urbanization: Retrospect and Prospects. In Tim Dyson, Robert Cassen \& LeelaVisaria (eds), Twenty - First Century India: Population,
Economy, Human Development and the Environment, Oxford University Press.

[12] Human Development Report (2012) United Nations Development Program, Oxford University Press.

[13] Human Development Report Tamil Nadu (2003) Social Science Press, Delhi 2003.

[14] Johannesson M \& Fagerberg B (1992), A health economic comparison of diet and any treatment in obese man with mild hypertension. Journal of Hypertension (1992):1063-1070

[15] Johannesson M \& Jonsson B, (1991), Economic evaluation in health care: is there a role of cost-benefit analysis. Health Policy. 17:1-23. Journal of Health Economics. 12:151-69.

[16] Kavitha S \& Ramu K (2010), Estimation of willingness to pay for rural health insurance in Nagapatinam District of Tamilnadu. Ph.D research proposal, Department of Economics, Annamalai University

[17] Kumaresan R \& Ramu K (2006) M. Phil thesis on Willingness to pay for primary health care services: A study in Komaratchi village Cuddalore District.

[18] Kumaresan R \& Ramu K (2012), Willingness to Pay for Secondary Health Care Services in Chidambaram Town, Cuddalore District. Annamalai Economic Papers, 6, 2009 (2009-10 and 2010-11): 47-51.

[19] Mangal (2004), Institutionalization of user charges in Government Hospitals in Rajasthan. Journal of Health Management, 6:1-5. http://dx.doi.org/10.1177/097206340400600101.

[20] Mari Bhat PN (2001) Indian Demographic Scenario 2025. Discussion Paper Series 27. IEG, 2001.

[21] Mathiyazhagan. K (1998) Willingness to pay for rural health insurance through community participation in India, International Journal of Health Planning and Management, 13: 47-67.

[22] Meeta Rajvlochal (2011), Inequities in Health. Economic and Political Weekly, 35(43) (2011): 41-46.

[23] Naryana KV (2003), Changing Health Care System. Economic and Political Weekly, 38(2):1230-1241.

[24] Peter Berman, Rajeev Ahuja \& Laveesh Bhandari (2010), The impoverishing effect on healthcare payments in India: new methodology and findings. Economic and Political Weakly, 59(16) 65-71

[25] Pranabbaradhan (2011), Challenges for a minimum social Democracy in India, Economic and Political Weekly, 36(10).

[26] Ramu K \& Selvarajan E (2011), An estimation of willingness to pay for secondary health care services in Tamil Nadu., Major Research Project Report, University Grants Commission, New Delhi.

[27] Ramu K, Sathyabama S \& Mathavan B (2007), Assessment of child delivery cost in private and public health care system: A micro level study in Moovalur village Nagapatinam District Tamil Nadu. Journal of Humanities, 44:415-426.

[28] Ramu K \& Elango R (2006), Ph.D. Thesis on Cost Effective Analysis of Control Strategies for Lymphatic Filarisis in Villupuram District of Tamilnadu. Department of Economics, Annamalai University.

[29] Ravi Duggal \& AbhyaShukla (2006), A Critique of health care policy in India. Economic and Political Weekly, 22(17):4579- 4589.

[30] Sharma BBL (2001), Health Financing in India: Some Issues. New Delhi: National Institute of Health and Family Welfare.

[31] Sharma, B.B.L. \& Bir T (2000), Willingness and economic capacity to pay for health care services. NIHFW, New Delhi, Unpublished study report.

[32] Statistical outline of India 2011-12, Tata Services Limited, Department of Economics and Statistics.

[33] Suganyasundari C \& Ramu K (2007) M.Phil thesis on Willingness to pay for secondary health care services: A study in Cuddalore Municipality, Cuddalore District.

[34] Thangalakshmi T \& Ramu K (2010), M.Phil thesis on Economic Analysis of Occupational Health Hazards of Neyveli Lignite Corporation Employees, Cuddalore District.

[35] World Bank (1993), Investing in Health, World Development Report, Oxford University Press, New York. 